\title{
Contraceptive methods among young married women in rural Burkina Faso: Challenges and motivations
}

\author{
I Ouedraogo, ${ }^{1} \mathrm{MD}$; S Kiemtore, ${ }^{2} \mathrm{MD}$; YA Sawadogo, ${ }^{2} \mathrm{MD}$; SR Sib, ${ }^{1} \mathrm{MD}$; H Zamane, ${ }^{2} \mathrm{MD}$; M Sanogo, ${ }^{1}$ MD; S Konkobo ${ }^{1}$, MS; \\ B Tieba-Bonane, ${ }^{2} \mathrm{MD}$ \\ ${ }^{1}$ Mother-child Department, Regional Teaching Hospital of Ouahigouya, Health Science Training and Research Unit, University of Ouahigouya, \\ Burkina Faso \\ ${ }^{2}$ Department of Gynecology and Obstetrics, Yalgado Ouédraogo Teaching Hospital of Ouagadougou, Health Science Training and Research Unit, \\ Joseph Ki Zerbo University of Ouagadougou, Burkina Faso
}

Corresponding author: I Ouedraogo (oued-issa2002@yahoo.fr)

\begin{abstract}
Background. Contraceptive prevalence remains low in developing countries. This low prevalence is not linked to unmet family planning needs, but rather to barriers to contraceptive use in women. One of the benefits of contraception is birth spacing and better development for the family. In Burkina Faso, few studies have been performed on the barriers and motivations to the use of contraception by young rural married women.

Objectives. We conducted a qualitative, descriptive, exploratory case study to understand the barriers and motivations to the use of effective modern methods of contraception by young married women in rural Burkina Faso.

Methods. Modern contraceptive methods were hormonal (oral or injectble) or intra-uterine devices. The sampling was non-probabilistic by reasoned choices. Data were derived from responses from individual in-depth semi-structured interviews, observations and a literature review. These were then analysed thematically.

Results. Gender relations unfavorable to women, the desire to have a large family, and shortcomings in communication constitute obstacles to the use of modern contraceptive methods. Despite these obstacles, the many benefits of modern contraceptives, namely the improving of health and family welfare and the empowerment of young women are a motivation to the use of effective contraception by young women, though this is dependant on partner support.

Conclusion. Despite the many obstacles to contraception, the many benefits motivate women to adhere to contraceptive methods.
\end{abstract}

S Afr J Obstet Gynaecol 2019;25(3):103-106. https://doi.org/10.7196/SAJOG.2019.v25i3.1459

The world's population surpassed 7 billion in October 2011..$^{[1,2]}$ Sub-Saharan Africa is one of the major contributors to this rapid population growth; its population could reach 2.1 billion by $20500^{[3]}$ This population growth, if not accompanied by economic growth and human development, will be the source of many social problems including poverty, conflict and migration. The National Institute of Stastistics and Demography (NISD) estimated the population of Burkina Faso at 16 million in 2011, 19.6 million in 2017, projected to reach 21.5 million by $2020 .^{[4]}$ This population increase is directly attributable to the low use of contraception. Survey data from the demography and health module of INSD, contraceptive prevalence for modern (nontraditional) effective methods in Burkina Faso in 2015 was $22.5 \% \cdot{ }^{[4]}$ This rate was $23 \%$ in Senegal, $15 \%$ in Ivory Coast and $70 \%$ in France. ${ }^{[4]}$ Aware of the challenges of population growth on development and in accordance with commitments made at international level, Burkina Faso committed itself to promote family planning. This commitment has resulted in successive steps to reposition family planning. These measures include: $(i)$ the adoption of a law on reproductive health in 2005, (ii) the community-based distribution of contraceptives in 2009, (iii) the subsidising of contraceptives in 2010, and (iv) the implementation of free family planning services in public health facilities since 2011.

Despite these efforts, unmet family planning needs remain high, at a current rate of $19.6 \% .{ }^{[4]}$ Much remains to be done to reduce the rate of this unmet needs in order to lower contraception rates which could rise to $32.5 \%$ in $2020 .{ }^{[4]}$ Modern contraception use remains low, globally. In developing countries, these have been attributed to three main factors: infrequent sexual intercourse, concerns about side effects or health risks, and accessibility to services offering contraceptive methods. In addition, sociocultural barriers and an ignorance of available contraceptive options contribute to underusage of modern contraceptive methods. These factors have have not sufficiently addressed by qualitative studies, specifically among young people in Burkina Faso. We conducted a study evaluating the barriers and motivations for modern contraceptive use among young married women in the health and social promotion center of Somiaga, Burkina Faso. Somiaga is a suburban village within the commune of Ouahigouya and based on a 2006 population census, Somiaga has an annual population growth rate above the average growth rate of Ouahigouya department. ${ }^{[10]}$ The rate of use of modern contraceptive methods at $3.38 \%$ in the first quarter of 2018 , is one of the lowest of the suburban Health and Social Promotion Center of Ouahigouya health district (unpublished data).

\section{Methods}

This was a qualitative, descriptive, cross-sectional study which took place from 23 July to 25 August 2018. The study population were young married women aged under 25 years of age attending 
the Health and Social Promotion Center of Somiaga. Nonprobabilistic sampling by reasoned choices was undertaken. ${ }^{[5]} \mathrm{A}$ diversified sample set was selected based on sociodemographic characteristics and included: district of origin, age, educational level, use or no use of modern contraceptive methods. This type of sampling is suitable because the aim was to choose participants who had either active or some experience of the studied phenomenon. ${ }^{[6]}$ Further inclusion criteria included: $>18$ years (of legal age), ability to speak 'Mooré' and consent by the participant. The choice of 'Mooré' is justified by the fact that it is a commonly spoken language in the region and was spoken by the research investigator without the need of a translator. The sample size was set at 12 young married women in line with literature on qualitative research that sets the sample size between $n=8$ and $n=12 .{ }^{[7]}$ Internal diversification was enabled when recruiting through the sociodemographic questionnaire. In order to sufficiently power our study, we used 15 participants. Three techniques were used to collect data: interview, observation and document review. Interviews were the main source of data. To preserve the anonymity and confidentiality of participants, recruitment and interviews were done in the same place. The interviews were recorded to allow transcription. All participants were informed about the research process (purpose, objectives, anonymity, confidentiality and the option to cease participation). All interviews took place after signed consent. In addition to discussions, analytical observations were made that enabled us to complete and triangulate collected information. Observation notes were recorded for health promotion and disease prevention activities around sexual and reproductive health within the health centre. Comments were made during individual interviews. The aim was to report reactions of a participant during interviews.

\section{Ethical considerations}

The study protocol was approved by the Ethics Committee for Health Research.

\section{Results Sociodemographic profile of the participants}

Our study included a total of 15 participants aged from 18 to 24 years. Seven participants were aged between 18 and 20 years. Six women who had 1 child, five had 2 children and four had 3 children. All five regions of the village were represented. The large majority of participants $(n=14 / 15)$ were Muslim, the predominant religion in the village of Somiaga (a single participant was Christian). Thirteen were in monogamous unions. Four participants had no education, five had completed primary education, six had completed secondary school and two were still pupils. Six participants had used or were currently using a modern contraceptive method and nine had never used any form of contraception. Regarding participants's husbands: three had no education, seven had completed primary education, and four had completed secondary school. Five were farmers, two worked in the building trade and two were traders. There was also a craftsman, a welder, a driver, an apprentice bricklayer and a husband who worked in agriculture in the the Ivory Coast. Many women $(n=9 / 15)$ could not report the exact age of their husbands, however reported ages were between 20 to 60 years. Of the six women who reported current or prior use of modern contraception, three were injectable (Depoprovera), two were implants (Jadelle) and one was a combined oral contraceptive.

\section{Barriers to the use of modern contraception: Aspirations and perceptions of fertility}

Responses by participants to questions on fertility were challenging to interpret given the sensitivity of the issue and a reluctance to provide comment. Common responses with respect to the desired number of children included: 'What God gives me' and 'I do not know yet.' After repeated requests for a personal position on the matter, some volunteered a desire for between 3 and 7 children. For some young married women, children are viewed as a symbol of wealth and prestige, therefore limiting the number of children is not considered desirable. One respondent, mother of one child, whose parents had 7 children, and the father-in-law had 2 wives and 12 children, illustrates this: 'Having many children can be a source of wealth because if some of them fail, others can succeed in life. For me, having many children is good because if one fails, the other can succeed. If one is not blessed, the other will be blessed. But if they are not numerous then there is no blessing (success), it's over. But if there are many, there is more likely to have blessing among them. Children may be considered a gift from God, and therefore human interventions or influences are meaningless. Here was the response of one woman, mother of three children, whose father has 2 wives and 14 children, and whose stepmother has 7 children: 'Really, we are not thinking about that. We say all that God gives us, that's what we want. All that God will desire, is what we follow. Because we cannot say we will do this and if this is not God's will, it will come true. You do not know where the blessing will come from. Success can come from the last children as it may come from first ones.' Another participant, a mother of 3 children whose stepfather had 3 wives and more than 20 children, and whose stepmother had 7 children, gave a similar response: 'Children are a gift from God. In all that he gives you, he places blessings which are gift, one can not judge it.' In response to the question 'how many children seem ideal to you?' she replied: 'Each has their choice. Some want many; others do not want too many. If I have six or seven, it is good for us to take care of them.' If children are considered a gift from God, equally, God can also take them back, rendering any human choice futile. An example of this opinion was expressed by a mother of one child: 'You can choose a number of children and God will remove what he wants. Your choice is meaningless.' Participants were asked about their perception regarding the risks of childbirth. Most responded that they were aware of risks but did not consider these risks as a factor when deciding to have childred. An example from a mother of one child, whose father has 3 wives and 16 children illustrates this: 'We cannot say that it is suffering and refuse to have children. We will have children.'

This attitude is reflected in the response of another participant: 'If I did not give birth! My mother wanted children, my father wanted children, but God didn't give them many. It is only me that he gave them. But as they (my parents) are no longer of this world, and it is I who stayed. Should I not give thanks to God for the children? He gives me so that my name will not disappear. We know that it can be difficult, but we will continue to deliver them.'

\section{Barriers to the use of modern contraception: The consent of husbands for contraception}

The consent of husbands naturally allows young married women to use modern contraception without leading to conflict. Consent from husbands may be age dependent as newly married or younger women are less likely to act on contraceptive use independently. Of 
the six women in our sample who had used modern contraception, the majority did so with the consent of their husband, as stated by one participant: 'Contraception? I have already used it and now, I'm still using it. I'm using Norplant [subdermal contraceptive implant]. My husband agrees with me on using contraception.' And from another participant: 'My husband had already previously allowed me to use contraception. I think that if I want to use contraception again, he will accept.' Some participants who had not used contraception were sure of the consent of their husbands, as exemplified by this response: 'We have not yet begun only; we are on our way. My husband will be informed before I use it. There will be no opposition.

\section{Motivations for the use of modern contraception}

The benefits of modern contraception provide motivations for their use among young married. These benefits can be grouped into two sub-themes: (i) improving health and family welfare and (ii) empowerment of young women. With respect to improving health and family welfare, all participants were unanimous in reporting the need to space births for the health and well-being of their families. A further benefit for the use of modern contraception is that they provide more freedom in conjugal life and therefore promote harmony within the marriage. Here are the reponses of a mother of twins who had already used modern contraception: 'Modern contraception does not prevent one from giving birth; its aim is to space births. It permits children to be healthy and mothers to rest. If you conceive a child who cannot tolerate his little [younger] brother, the baby is crying, and his elder brother is crying too, it becomes hard for you.' She continues: 'For example, I hold these two babies [twins]; if their elder brother was still small, two years or less than two years, the situation would be difficult. But their elder brother is 5 years old.' And further: 'Some women are fast, others slower; but we cannot know. We must take some precautions to space births.' With reference to contraception as a means of promoting marital harmony, this is the response of an 18-year-old mother of one child, who was not using contraception: 'If you manage to use contraception, you live in a good understanding with your husband. There are no disputes between you. If you use contraception, you are well; you have no more worries.' When asked why she was not already using contraception, she replied: 'We are going to do it. We have not yet begun; we're on our way.' Some participants also noted that modern contraception provides freedom in married life and contributes to a good understanding within the couple, as this active user describes: If contraception is used, there are no more problems in the relationship between the woman and her husband.' This is echoed by a participant who had never used contraception but was aware of the advantages already cited: 'If it suits you, there are many advantages: you'll be in good health and you'll feel well.' The use of modern contraceptive methods is perceived by some women as being a potential conflict mitigator, as illustrated by the response of one participant: 'I've never used modern contraception, but I know that it helps a bit. Even if it is the 3-month [injectable] that you use, if it suits you, your child is healthy and you yourself are healthy. Hai! Men of today like small quarrels. Perhaps, small quarrels will decrease.' The use of contraception empowers young married women, allowing them to work independently and generate income. Several participants alluded to this: 'The use of modern contraception allows the woman to choose the best time for her motherhood. The advantage is the possibility to wait for a long time before giving birth. If you do not use modern contraception, you will quickly give birth; but if you use it and it suits you, you will give birth at the time you want.' From another participant: 'You can take better care of your business. When I used it in the dry season, I could sell water and earn some income to my grind millet and buy clothing items, clothes and shoes.' From another: 'Look at this child, if he does not reach 2 years or a year and a half and you get pregnant, it does not make sense; your business will suffer. If you get pregnant, you cannot do anything.' And another: 'If you] do not use it and you find yourself with serious diseases, you are in trouble. Contraception helps people in their economic activities.'

\section{Discussion}

This study reports on the barriers to modern contraceptive use and the factors that motivate their use among young married women in Burkina Faso.

\section{Aspirations and perceptions of fertility}

Questions around fertility were not easy to address because of the sensitive nature of the subject among young women. This was reflected in the attitudes of participants when asked about fertility, despite their willing participation in the overall study. This difficulty was also mentioned in the report of the last demographic and health census of 2010. ${ }^{[1]]}$ Notwithstanding this difficulty, we attempted to analyse the perception of fertility through the words and attitudes of young married women. As alluded to by Bongaarts et al..$^{[8]}$ fertility rates are higher in sub-Saharan Africa because people are poorer, less educated and have a desire for large families. This desire for a large family is a hindrance to the use of modern contraception, particularly among young married women who begin their productive life. The reported number of children desired by young women in a marital union varies in this study between 4 and 6 children. These numbers of desired children are in line with findings by Guengant et al. ${ }^{[9]}$ who report that the synthetic fertility index average per woman is five children. However, these extremes are well above the Planned National Development Economic and Social (PNDES) goals of Burkina Faso, which aim to bring the total fertility rate (TFR) from 5.4 to 4.7 children by 2020 . Some participants in our study already had 3 children, highlighting the desire for large families and are examples of high fertility among young women in Burkina Faso. Figures from a 2010 Demographic Health Survey report show high fertility rates in young women (130\% for $15-19$ years), which increases rapidly, peaking at $25-29$ years (269\%). ${ }^{[10]}$ Environment contributes to high fertility rates as young women in rural areas are more likely to marry earlier as compared with urban centres.

\section{Motivations for the use of modern contraception}

Participants reported many benefits of using contraception. These included: birth-spacing, rest, better health, freedom in married life, work and carrying out economic activities. We have grouped these benefits into two sub-themes which are: (i) improving health and family welfare; and (ii) empowerment of women. Birth-spacing, health, freedom in conjugal life and understanding within the couple were cited repeatedly. We acknowledge that the use of modern contraception has more benefits than risks. The balance between the benefits and risks are an important motivating factor. This is appreciated by many couples especially the more educated. This finding is consistent with the results of numerous studies that have shown that the use of modern contraception increases with the level of education. ${ }^{[11,12]}$ 
Most of the cited benefits of modern contraceptive use in this study are consistent with those reported in a 2015 Rwandan study. ${ }^{[13]}$ An extract from a 38 year old female community member in that study is as follows: '(Without family planning) you can give birth to many children and your life becomes very complicated. Now I have only 2 children and their life is very different from (what it would be) if I had 5 children. When you give birth to many children... they need soap and clothing and they will often be dirty. So, for me, family planning use was good, and I would even educate those who are not yet using family planning to start.' How can we still prevent women from enjoying their recognised rights? Efforts should be made at all levels to minimise the barriers to the use of modern contraception, especially gender relationships unfavourable to women.

\section{The consent of husbands}

This theme is closely linked to the health of the relationship between the man and his wife. The disapproval of the husband presents an obstacle; however, their consent was a motivating factor for modern contraceptive use. Women in our study who had used contraception with the consent of their husbands were visibly delighted. Most studies from Burkina Faso have not evaluated husband's consent in determining contraceptive use but evaulate family support. A study by Muanda et al..$^{[14]}$ in the Democratic Republic of Congo however states the following: 'The husband's support to the use of family planning has been a decisive factor in the decision of a couple. Participants explained that the judgment of their husbands took precedence over the approval or disapproval of any other family member or friend.'

This point of view is also supported by Ochako et al. ${ }^{[15]}$ in a 2015 Kenyan study that highlighted the influence of husbands in the decision-making process of contraceptive use. Therefore, Yeaky and Yeakes and Gilles ${ }^{[16]}$ recommend that family planning and awareness programs should not neglect men as they play an important role in the use of modern contraception.

\section{Conclusions}

Family planning is key in acheiving sustainable development goals, particularly in sub-Saharan Africa. Our study of young married women in Burkina Faso show that the barriers to contraception are sociocultural factors, unfavorable gender relations and a deficit in communication. The benefits of contraception namely improved health and family welfare and women's empowerment are motivations to contraceptive use in this society.

Acknowledgements. The chief doctor of the Health District of Ouahigouya who authorised the study and all the support from the health centre staff of Somiaga. Author contributions. All authors contributed to the writing of the present study. Funding. None.

Conflicts of interest. None.

1. Guengant JP, May JF. L'Afrique subsaharienne dans la démographie mondiale. Études 2011, 415(10):305-316

2. United Nations Population Fund. State of the World Population in 2011: 7 billion People, Their World, Their Possibilities. https://www.unfpa.org/sites/default/files/pub-pdf/EN-SWOP2011-FINAL pdf (accessed 22 October 2019).

3. May JF, Guengant JP, Barras V. Demographic challenges of the Sahel countries. In: Groth H, May J eds. Africa’s Population: In Search of a Demographic Dividend. Springer: Switzerland, 2017:165-176. https://doi.org/10.1007/978-3-319-46889-1_11

4. Burkino Faso Ministry of Health. National Plan for Accelerating Family Planning (2017-2020):17-44 http://www.healthpolicyplus.com/ns/pubs/8212-8375_PNAPF.pdf (accessed 22 October 2019).

5. Pires AP. [Sampling and qualitative research: theoretical and methodological test. Qualitative research. Epistemological and methodological issues] 1997:113-169. https://doi.org/10.1522/030022877

6. Borgès $\mathrm{Da}$, Silva G. [Qualitative research: Another type of action and communication]. Rev Med Ass Maladie 2001;32(2):117-121.

7. Aubin-Auger I, Mercier A, Baumann L, Lehr-Drylewicz AM, Imbert P, Letrilliart L. Introduction to qualitative research. Exercer 2008;84(19):142-145.

8. Bongaarts J. Can family planning programs reduce the desire for large families in sub-Saharan Africa? Int Perspect Sex Reprod Health 2011;37(4):209-216. https://doi.org//10.1363/3720911

9. Guengant JP, Stührenberg L. [Ask the question of demography in west Africa]. Grain de Sel; 2013;59:45-46. http://www.documentation.ird.fr/hor/fdi:010067318

10. National Institute of Statistics and Demography. Demographic and health survey and multiple indicators report. Burkina Faso, 2012. http://www.insd.bf/n/contenu/enquetes_recensements/enq_ demo_sante/edsbf_mics_rapport_definitif.pdf (accessed 22 October 2019).

11. National Institute of Statistics and Demography, Burkina Faso. Demographic and health survey and multiple indicators (EDSBF-MICS IV) Report 2010. http://www.insd.bf/n/contenu/enquetes recensements/enq_demo_sante/edsbf_mics_rapport_definitif.pdf (accessed 22 October 2019)

12. Sedgh G, Hussain R. Reasons for contraceptive nonuse among women having unmet need for contraception in developing countries. Stud Fam Plann 2014;45(2):151-169. https://doi.org/10.1111/ j.1728-4465.2014.00382.x

13. Farmer DB, Berman L, Ryan G, et al. Motivations and constraints to family planning: A qualitative study in Rwanda’s southern Kayonza district. Glob Health Sci Pract 2015;3(2):242-254. https://doi org/10.9745/GHSP-D-14-00198

14. Muanda MF, Ndongo GP, Messina LJ, Bertrand JT. Barriers to modern contraceptive use in rural areas in DRC. Cult Health Sex 2017;19(9):1011-1023. https://doi.org/10.1080/13691058.2017.1286690

15. Ochako R, Mbondo M, Aloo S, Kaimenyi S, Thompson R, Temmerman M, Kays M. Barriers to modern contraceptive methods uptake among young women in Kenya: A qualitative study. BMC Pub Health 2015;15:118. https://doi.org/10.1186/s12889-015-1483-1

16. Yeake MP, Gilles KP. Expanding Contraceptive Methods for Successful Family Planning Programs. https:/ www.prb.org/method-choice-for-successful-family-planning-programs. (accessed 22 October 2019)

Accepted 15 January 2020 